\title{
UM CURRÍCULO EM CONSTRUÇÃO: PERCEPÇÃO DE PROFESSORES QUE ENSINAM MATEMÁTICA NA EDUCAÇÃO DE JOVENS E ADULTOS
}

\author{
LIMA, Reinaldo Feio ${ }^{1}$
}

\section{INTRODUÇÃO}

A justificativas deste artigo esbarra na atual necessidade de aprofundamento das discussões sobre a formação docente voltada para contextos em que existe grande diversidade cultural (ARROYO, 2008), como no caso da educação de jovens e adultos. Assim, o objetivo foi compreender a percepção de professores que ensinam matemática na Educação de Jovens e Adultos (EJA) sobre a construção do currículo e os desafios do trabalho docente na EJA.

Portanto, a formação de professores que ensinam Matemática na EJA passou a ocupar um espaço significativo na minha atuação profissional da Educação, após as experiências em duas escolas públicas da cidade de Tailândia no estado do Pará. A partir desse momento, passei a ter um olhar diferenciado em relação à prática pedagógica do professor. Este trabalho é fruto de reflexões desenvolvidas pelo autor ao longo de sua experiência como professor da EJA, professor de cursos de formação de professores e pesquisador no campo da EJA.

Assim, entre os desafios que se apresentam à EJA inclui-se a luta por mudanças no âmbito da Prática Pedagógica, re-significando os conteúdos e dando a necessária relevância aos conhecimentos que esses alunos já possuem. A motivação para a presente proposta emerge do pressuposto de que todos os profissionais da educação devem refletir sobre suas práticas pedagógicas em algum nível. Nessa proposta, uma questão sempre esteve presente em minhas reflexões, como professor de Matemática e, em especial, como pesquisador, foi compreender os processos de ensino e aprendizagem da Matemática.

\section{METODOLOGIA}

\footnotetext{
${ }^{1}$ Professor Assistente Mestre da Universidade Federal do Sul e Sudeste do Pará, Campus Universitário de Santana do Araguaia. reinaldo.lima@unifesspa.edu.br. Trabalho apresentado com o apoio da Propit/Unifesspa.
} 
Devido aos objetivos de estudo, optou-se por um a abordagem qualitativa de pesquisa (CERVO; BERVIAN, 2002) de carácter exploratório, por ser essa uma abordagem possível para uma investigação sobre concepções.

Assim, se enquadrará na modalidade de pesquisa qualitativa, que segundo Fiorentini e Lorenzato (2006, p. 110), "busca retratar a realidade de forma profunda e mais completa possível, enfatizando a interpretação ou análise do objeto, no contexto em que ele se encontra".

Dessa maneira, a proposta desenvolverá num enfoque descritivointerpretativo, numa abordagem qualitativa, considerando que nesta tem-se o ambiente natural como fonte direto dos dados; todos os dados coletados são importantes e predominantemente descritivos; a preocupação maior com o processo, com a complexidade da trajetória dos participantes; os significados que as pessoas dão às coisas e à sua vida são objeto de atenção do pesquisador; a análise dos dados segue um processo indutivo (BOGDAN e BIKLEN, 1994).

Logo, buscará desenvolver uma investigação sob a perspectiva da pesquisa qualitativa, levando em consideração que a escolha de procedimentos e técnicas apropriadas é ponto fundamental para o desenvolvimento e a fidedignidade dos resultados da pesquisa (ROSA e ARNOLDI, 2006). Buscando o caráter dialógico, construtivo-interpretativo e pela valorização dos sujeitos (GONZALES REY, 2005).

A opção pela pesquisa qualitativa se justifica também porque segundo Bicudo (2004) privilegia descrições de experiências, relatos de compreensões, respostas aos questionários, entrevistas com sujeitos, relatos de observações e outros procedimentos que deem conta de dados sensíveis, de concepções, de estudos mentais, de acontecimentos, etc.

A escolha da entrevista como método de recolha de informação complementar, fundamenta-se nas concepções de (MANZINI, 1991), que se construirá por meio de um roteiro previamente elaborado composto de questões abertas e fechadas.

A observação participante é um instrumento fundamental na pesquisa de campo, muito utilizada pelos pesquisadores qualitativos para coleta de dados. Para Fiorentini e Lorenzato (2009), a observação participante é um tipo de estudo naturalista, pois o pesquisador frequenta o local onde os fenômenos ocorrem de forma natural. Além disso, "a coleta de dados é realizada junto aos comportamentos 
naturais das pessoas quando estas estão conversando, ouvindo, trabalhando, estudando em classe, brincando, comendo..." (FIORENTINI; LORENZATO, 2009, p. 107).

Os procedimentos utilizados foram: observação participante e entrevista, realizada com quatro professores que lecionavam no Programa de Educação de Jovens e Adultos da Secretaria Municipal de Santana do Araguaia, que participavam da Semana Pedagógica organizada e oferecida pela SEMED.

Os professores sujeitos desta pesquisa apresentaram formação acadêmica diferenciada. Os participantes das entrevistas foram identificados atribuindo-se a sigla A, B, C e D aos professores. Isso contribuiu para, caso fosse necessário, acessar as entrevistas novamente sem identificar os sujeitos e resguardar o direito de imagem. A construção do roteiro das entrevistas (AlvesMazzotti, 1998) deste estudo teve tópicos que foram seguidos de forma flexível, afim, de alcançar os objetivos, a medida que foram sentidas as necessidades, foram sendo modificadas para uma melhor compreensão da fala dos sujeitos.

As entrevistas foram analisadas tendo como referência a técnica de Análise Textual Discursiva (MORAES, GALIAZZI, 2006, 2011). Uma técnica que pode ser compreendida como um processo auto-organizado de construção de compreensão em que novos entendimentos emergem de uma sequência recursiva de três componentes: desconstrução do corpus, a unitarização e a categorização (MORAES, 2003).

A unitarização objetiva examinar o material do corpus em detalhes, por meio de um processo de desmontagem dos textos, no qual se dá destaque aos seus elementos constituintes. Em seguida, surgem as unidades de análise ou unidades de significado, que são obtidas da fragmentação do corpus e posterior codificação. Cada unidade é reescrita de modo que assuma um significado o mais completo possível em si mesmo. Finalizando, atribui-se um nome ou um título para cada unidade assim produzida (MORAES, 2003).

Dessa maneira, trilhamos as etapas sugeridas por Moraes (2003) para a análise textual discursiva, realizou-se uma leitura minuciosa, com o objetivo de obter as primeiras impressões e ideias gerais do corpus. Em seguida, desmontamos os textos com o objetivo de identificar os principais elementos que os caracterizam, de modo que cada um dos textos ficasse fragmentado em frases ou sentenças que 
julgamos expressar ou descrever os principais argumentos e ideias do autor quanto ao trabalho.

\section{RESULTADOS E DISCUSSÕES}

Fragmentos:

1. "No ano passado, não conseguir trabalhar todos os conteúdos, porque tinha muitas datas comemorativas, faltas dos alunos e falta de energia elétrica (Professor A)".

2. "Comigo não foi diferente, no meu caso, a maior dificuldade em desenvolver os conteúdos, foi a dificuldade dos meus alunos com a Matemática (Professor B)".

3. Bom... Não conseguir trabalhar nem a metade do conteúdo previsto para o ano letivo do ano passado, resolvi ficar nas 4 operações básicas e buscava trabalhar com outros conteúdos (Professor C)".

4. Concordo com vocês, na minha escola, a maior dificuldade que enfrento é a distorção serie e idade dos meus alunos, que acaba ocasionando, extrema dificuldade com os conteúdos de Matemática, sem contar com meus alunos estão a bom tempo sem estudar (Professor D)".

No decorrer da observação participante durante construção do currículo que seria utilizada pelos professores no ano letivo de 2016, ficou evidente que a lotação desses professores não levou nenhum critério para que os pudessem trabalhar nesta modalidade de ensino. No que se refere às licenciaturas, verifica-se a quase total ausência de espaços de discussão dos processos de ensino e aprendizagem na EJA nos cursos de formação de professores de Matemática, e outras disciplinas.

Assim, ambos não tinham formação ou não fizeram curso de formação para atuar nessas turmas. Além disso, $100 \%$ dos professores participantes tem graduação em Matemática, mas complementam sua carga horária com outras disciplinas, como: Ciências "Eu mesmo só tenho 100 horas de Matemática, o restante com disciplinas de Ciências, e vou me virando como posso (Professora B). Como não há uma formação específica, os professores para atenderem as necessidades de seus alunos, devido a falta de um arcabouço teórico-metodológico "traduzem sua formação e a adaptam à profissão" (TARDIF, 2002, p. 53). 
Nas falas dos professores observou-se que o currículo da EJA é muito extenso, cabendo aos professores seguir um livro que é escolhido pela SEMED, em que o conteúdo para serem ministrado durante o ano letivo se torna inviável devido as dificuldades: muitos anos ausente da escola, motivação, dificuldade de aprendizagem, falta, desistências, etc. Segundo os professores uns dos grandes desafios encontrados na sala de aula: diferenças marcantes de idade, que podem incluir jovens de 15 anos a idosos de 65 anos, e metodologias capazes de envolver o aluno plenamente nas atividades de ensino, ou seja, a busca por construção de estratégias pedagógicas que lidem com as aprendizagens de fora da escola e da escola (DOMITE, 2004). Ficou evidenciado que os professores tem autonomia selecionar conteúdos de ensino que estejam mais adequados aos seus alunos "dependendo do que eu acredito que seja importante para a vida do meu aluno, eu ensino, procuro selecionar os conteúdos que possam ter aplicabilidade na vida cotidiana" (Professor C).

Portanto, os professores que atuam nesta modalidade de ensinam precisam e necessitam de formação continuada para trabalhar na EJA, como fica registrado na fala do Professor A "nós somos os que mais precisa de formação, ou até mesmo de oficina para trabalhar com nossos alunos, sinto por de mais isso na minha formação". Isso nos leva a refletir sobre a real necessidade de se oferecer formação continuada afim de possibilitar as reflexão sobre os processos de ensino e aprendizagem dos adultos, permitindo aos profissionais autonomia na construção do currículo e, consequentemente, o estímulo à autonomia intelectual de seus alunos.

\section{CONSIDERAÇÕES FINAIS}

Nos diferentes momentos em que participamos da semana pedagógica, no que tange, os professos da construção do currículo e os desafios do trabalho docente na EJA, percebemos o vigor das discussões que esses profissionais precisam e devem ser ouvidos, com intuito de fomentar espaços e tempos de formação, em que possam de forma colaborativa reunir com seus pares para estudar, trocar experiências, questionar o proposto, discutir com os especialistas/formadores, reinventar a formação com todos os envolvidos no processo de ensino e aprendizagem. Por isso, defendemos a importância da formação continuada, sobretudo de médio a longo prazo, abrindo o espaço para os 
professores fazerem afluir, discutir, dialogar, analisar seus dilemas pedagógicos que circulam os seus afazeres pedagógicos.

\section{REFERÊNCIAS}

ALVES-MAZZOTTI, Alda Judith. Representações da identidade docente: uma contribuição para a formulação de políticas. Ensaio: Avaliação e Políticas Públicas em Educação. Rio de Janeiro, v. 15, n. 57, p. 579-594, out./dez. 2007. Disponível em: < http://www.scielo.br/pdf/ensaio/v15n57/a08v5715.pdf >. Acesso em: fev. 2016.

ARROYO, M. G. Os coletivos diversos repolitizam a formação. In: DINIZ- PEREIRA, J. E.; LEÃO, G. (Org.). Quando a diversidade interroga a formação docente. Belo Horizonte: Autêntica, 2008. p. 11-36.

BICUDO, M.A.V. Pesquisa quantitativa e pesquisa qualitativa segundo a abordagem fenomenológica. In: BORBA, M.C. ARAUJO, J.L. (Orgs.). Pesquisa qualitativa em educação matemática. Belo Horizonte: Autêntica, 2004

BOGDAN, R. e BIKLEN, S. Investigação Qualitativa em Educação. Porto: Porto Editora, 1994.

CERVO, A. L.; BERVIAN, P. A. Metodologia Científica. 5a ed. São Paulo: Prentice Hall, 2002.

DOMITE, M. C. S. Da compreensão sobre formação de professores e professoras numa perspectiva etnomatemática. In: KNIJNIK, G.; WANDERER, F.; OLIVEIRA, C. J. (Org.). Etnomatemática: currículo e formação de professores. Santa Cruz do Sul: EDUNISC, 2004. p. 419-431.

FIORENTINI, D.; LORENZATO, S. Investigação em educação matemática.

Percursos teóricos e metodológicos. Campinas, SP: Autores Associados, 2006.

; LORENZATO, S. Investigações em educação matemática: percursos

teóricos e metodológicos. 3. ed. rev. Campinas: Autores Associados, 2009.

GONZALES REY, F. Pesquisa Qualitativa e Subjetividade - Os processos de construção de informação. Tradução: Marcel Aristides Ferrada Silva. São Paulo: Pioneira, 2005.

MANZINI, E. J. A entrevista na pesquisa social. Didática, São Paulo, v. 26/27, p. 149-158, 1991.

MORAES, R. Uma tempestade de luz: a compreensão possibilitada pela análise textual discursiva. Revista Ciência e Educação, v. 9, n. 2, p. 191-211, 2003.

MORAES, R; GALIAZZI, M. C. Análise textual discursiva: processo construído de múltiplas faces. Ciência \& Educação, v.12, n.1, p.117-128, 2006. 
MORAES, R; GALIAZZI, M. C. Análise Textual Discursiva. Ijuí: Editora Unijuí, 2011.

ROSA, Maria Virgínia de F. P. C; ARNOLDI, Marlene A. G. C. As entrevistas na pesquisa qualitativa: mecanismos para a validação dos resultados. Belo Horizonte: Autêntica, 2006.

TARDIF, M. Saberes docentes e formação profissional. Petrópolis: Vozes, 2002. 